NBS

NBSIR 81-2314

\title{
Migration of Low Molecular Weight Additives in Polymers
}

IJ.S. DEPARTMENT OF COMMERCE National Bureau of Standards Center for Materials Science Polymer Science and Standards Division Washingten, DC 20234

Eemi-Annual Report for the Period October 1, 1980 - March 31, 1981

Issued September 1981

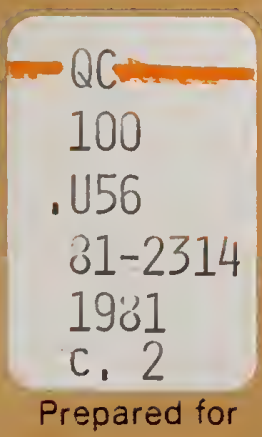

Bureau of Foods

Food and Drug Administration Washington, DC 20201 



\section{MIGRATION OF LOW MOLECULAR WEIGHT ADDITIVES IN POLYMERS}

L. E. Smith, S. S. Chang, and

G. A. Senich

U.S. DEPARTMENT OF COMMERCE

National Bureau of Standards

Center for Materials Science

Polymer Science and Standards Division

Washington, DC 20234

Semi-Annual Report for the Period

October 1, 1980 - March 31, 1981

Issued September 1981

Prepared for

Bureau of Foods

Food and Drug Administration

Washington, DC 20201

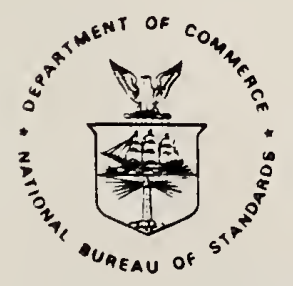

U.S. DEPARTMENT OF COMMERCE, Malcolm Baldrige, Secretary NATIONAL BUREAU OF STANDARDS, Ernest Ambler, Director 

Migration of Low Molecular Weight Additives in Polymers

Semiannual Report for the Period:

October 1, 1980 - March 31, 1981

L. E. Smith, S. S. Chang, and G. A. Senich

Polymer Science and Standards Division

Apri1 29, 1981

This is a progress report of continuing work for the internal uses of a sponsoring agency. The results are incomplete and the conclusions are necessarily tentative. Any or all of the material in this report may be modified before the final report is issued. 



$$
\text { Table of Contents }
$$

Summary ........................ 1

I. Extraction of Polyethylene with $0 i 1$ Simulating Solvents . . . . 3

A. Comparison of n-Octanol and Ethanol

Extractions .............. . . 3

B. Comparison of Synthetic Triglyceride Mixture HB307 to Corn Oil . . . . . . . . . . . . . 7

C. Effects of 5\% Water on Ethanol Extractions . . . . . . 13

II. Migration of BHT from Ethylene Vinyl Acetate Copolymers . . . . . 21

III. Migration of VCM from PVC . . . . . . . . . . . . . . . 27

IV. Review of the Migration of Organotin Compounds from PVC . . . . . . 29 

Surmary

In the first half of the FY81, several new areas were investigated. In testing and searching for oil-simulating solvents, we have studied the extraction behavior of (a) n-octanol, an extracting solvent used widely in biological and environmental studies, (b) HB307, a synthetic triglyceride mixture used widely in Europe as food-oil simulant and (c) $95 \%$ ethanol, to assess the effect of $5 \%$ water on the extractability of anhydrous ethanol. Antioxidant migration in two (ethylene-vinyl acetate) copolymers having vinyl acetate contents of $5 \%$ and $13 \%$ is being investigated for comparison with the polyolefin data. We are also beginning investigations of vinyl chloride migration from poly(vinylchioride). The following summarizes some preliminary conclusions from these studies.

n-Octanol vs. Ethanol

Diffusion coefficients of the three migrants from branched polyethylene into n-octanol are about the same or slightly greater than those into ethanol at both 30 and $60^{\circ} \mathrm{C}$. However, for migration of $\mathrm{BHT}$ from Tinear polyethylene, the diffusion coefficients may be 2 to 4 times higher for extractions with $n$ octanol compared to ethanol. HB307 v5. Ethanol or other Triglycerides

Diffusion coefficients of the three migrants mentioned above were measured from branched polyethylene into HB307, a synthetic triglyceride mixture, at 40 and $60^{\circ} \mathrm{C}$. The diffusion coefficients are found to ve about equal to those for extractions into ethanol or other triglycerides, as expected. 95\% Ethanol vs. Anhydrous Ethanol

The diffusion coefficients into $95 \%$ ethanol are generaliy reduced by a factor of $2 / 3$ to $1 / 2$ of those into anhydrous ethanol. However, the amount extractable by $95 \%$ ethanol is more strongly governed by a change in the partition coefficient, as a result of reduced solubility of some of the migrants such as $n-C_{32}{ }^{H} 66$ in $95 \%$ ethanol. 
BHT from Ethylene-Vinyl Acetate Copolymers

Diffusion coefficient measurements of BHT from (ethylene-5\% vinyl acetate) copolymer are currently in progress. In n-heptane, the diffusivity of BHT in the copolymer is only slightly higher than in branched polyethylene. However, at $60^{\circ} \mathrm{C}$ the diffusion coefficients into ethanol and corn oil are about three times greater than those for branched polyethylene extractions. 
I. Extraction of Polyethylene with 0 il Simulating Solvents A. Comparison of n-Octanol and Ethanol Extractions

n-Octanol has been used widely in biological and environmental studies as an extracting solvent. We have studied the migration behavior of $n$ $\mathrm{C}_{18} \mathrm{H}_{38}, \mathrm{n}-\mathrm{C}_{32} \mathrm{H}_{66}$, and BHT from both linear and branched polyethylenes into $n-$ octanol at 30 and $60^{\circ} \mathrm{C}$. The results are compared with those from ethanol extractions in Table 1 and sumarized in Figure 1.

n-Octanol generally behaves as a slightly accelerating solvent for all three migrants, differing from results for anhydrous ethanol by a factor of less than 1.3. Only in the case of BHT migration from LPE is a greater accelerating factor of 3 to 4 evident. The large increase in the diffusion coefficient in this case may be due to the increased mobility of degraded fragments from BHT in this particular sample. This speculation is impossible to confirm without performing a full analysis.

In the case of $n-C_{32}{ }_{66}$ migration, where partition coefficients are measureable in both ethanol and n-octanol extractions, the partition coefficients for n-octanol are nearly twice those of ethanol.

Thus, n-octanol is a slightly accelerating solvent when compared to ethanol and also allows a larger amount of oligomer to be extracted at equilibrium. 


$$
\begin{aligned}
& \text { Table } 1 \\
& \text { Additive Migration into Ethanol and n-Octanol } \\
& 0, \mu \mathrm{m}^{2} \mathrm{~s}^{-1}
\end{aligned}
$$

\begin{tabular}{|c|c|c|c|c|c|c|}
\hline \multirow{2}{*}{ Sample Code } & \multirow[b]{2}{*}{ Polymer } & \multirow[b]{2}{*}{ Migrant } & \multicolumn{2}{|c|}{ Ethanol } & \multicolumn{2}{|c|}{ n-octanol } \\
\hline & & & $30^{\circ} \mathrm{C}$ & $60^{\circ} \mathrm{C}$ & $30^{\circ} \mathrm{C}$ & $60^{\circ} \mathrm{C}$ \\
\hline \multirow[t]{2}{*}{1,2} & LPE & $\mathrm{C18}$ & 0.018 & & 0.022 & \\
\hline & & & & 0.52 & & 0.70 \\
\hline \multirow[t]{2}{*}{7,9} & BPE & $\mathrm{C} 78$ & 0.061 & & 0.065 & \\
\hline & & & & 3.0 & & 3.6 \\
\hline 16 & $B P E$ & C32 & & 0.29 & & 0.35 \\
\hline 19 & LPE & C32 & & 0.063 & & 0.047 \\
\hline \multirow[t]{2}{*}{22} & LPE & BHT & 0.0019 & & 0.0087 & \\
\hline & & & & 0.047 & & 0.14 \\
\hline \multirow[t]{2}{*}{25} & BPE & BHT & 0.038 & & 0.045 & \\
\hline & & & & 1.0 & & 1.3 \\
\hline
\end{tabular}




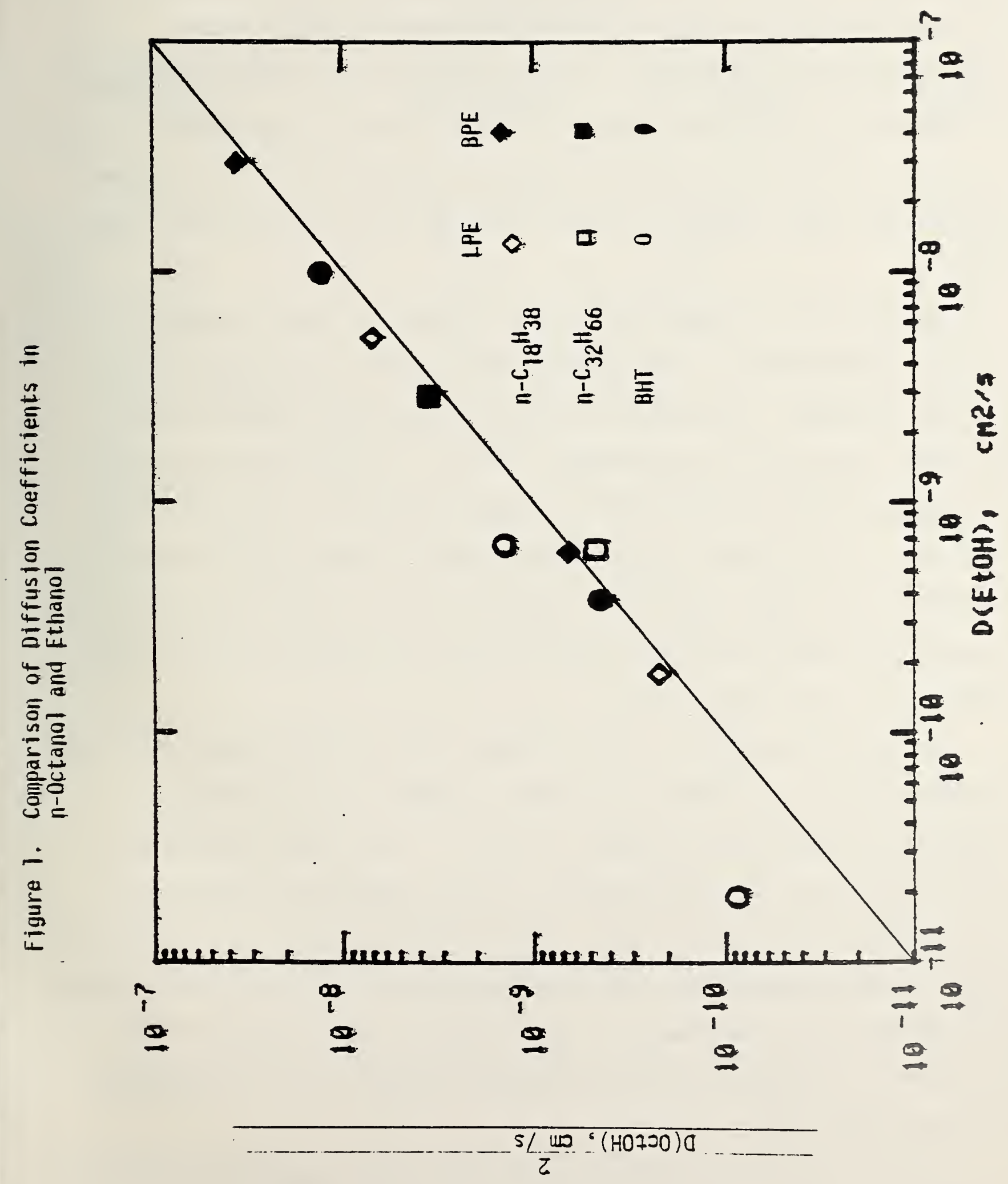


B. Comparison of Synthetic Triglyceride Mixture HB3O7 to Corn Oil

The synthetic triglyceride mixture $H B 307$ has been used quite widely in some European laboratories as a food-oil simulant for extraction purposes. The particular sample of $\mathrm{HB} 307$ received by us differs slightly from the "typical" melting point of $28^{\circ} \mathrm{C}$. It melts completely at $31-34^{\circ} \mathrm{C}$ as determined by differential scanning calorimetry. Because of the high melting point, extractions of the three migrants $\left(n-\mathrm{C}_{18} \mathrm{H}_{38}, n-\mathrm{C}_{32} \mathrm{H}_{66}\right.$, and $\left.B H T\right)$ from branched polyethylene (sample codes 9,16 and 25) with HB307 were performed at 40 and $60^{\circ} \mathrm{C}$.

The extraction data for $H B 307$ at $60^{\circ} \mathrm{C}$ are shown in Figure 2 together with the corresponding corn oil data obtained previously and nomalized to the same thickness. The results for branched polyethylene extractions by both HB307 and corn oil are summarized in Table 2. It can be seen that for $n-\mathrm{C}_{18} \mathrm{H}_{38}$ the diffusion coefficients into HB307 are slightly lower than those into corn oil. For both $n-\mathrm{C}_{32} \mathrm{H}_{66}$ and BHT however, diffusion coefficients into $H B 307$ are slightly higher than those into corn oit. In all the cases studied, the change in diffusion coefficient due to a change from corn oil to HB307 is less than a factor of 1.5.

The activation energies of the oligomers migrating from branched polyethylene into either corn oil or HB3OT are in better agreement than the diffusion coefficients themseives as indicated in Table 3. The diffusion coefficients of $n-C_{32}{ }_{66}$ follow the same temperature variation regardless of whether corn oil or HB307 is used as the solvent. The extraction of $n-\mathrm{C}_{32} \mathrm{H}_{66}$ by trioctanoin also follows the same course. This is illustrated in Figure 3 for the extraction of branched polyethylene (sample 25) by the three different triglycerides. The activation energies for BHT and $n-C_{18} H_{38}$ extracted by corn $0 i 1$ and $H B 307$ are also quite similar.

It may be concluded that the diffusion coefficients determined by extracting with all liquid trigtycerides are identical well within a factor of 1.5 and the activation energies are probably within a factor of 1.3. 


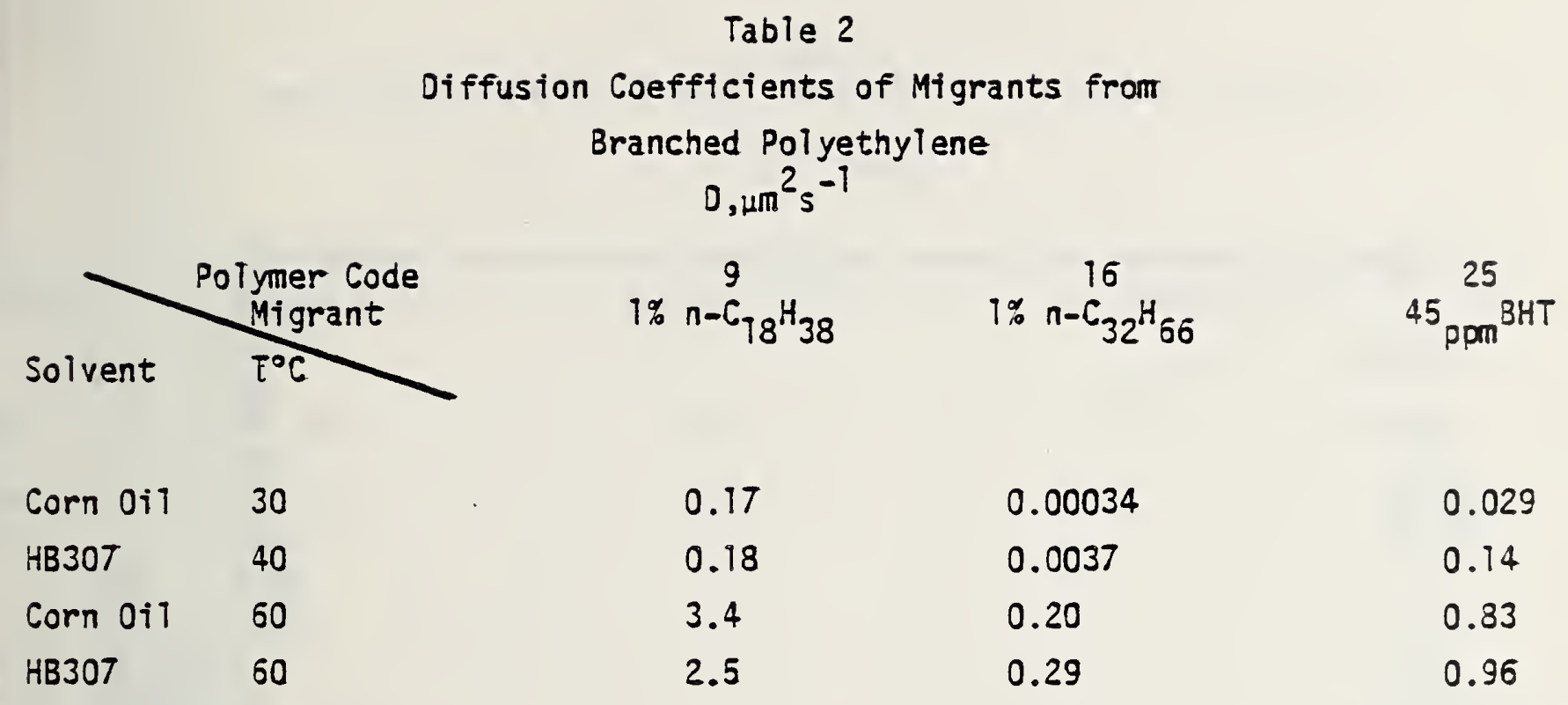


Table 3

Activation Energies for Migration from Branched Polyethylene $E_{\text {act }}$, kJmol $^{-1}$
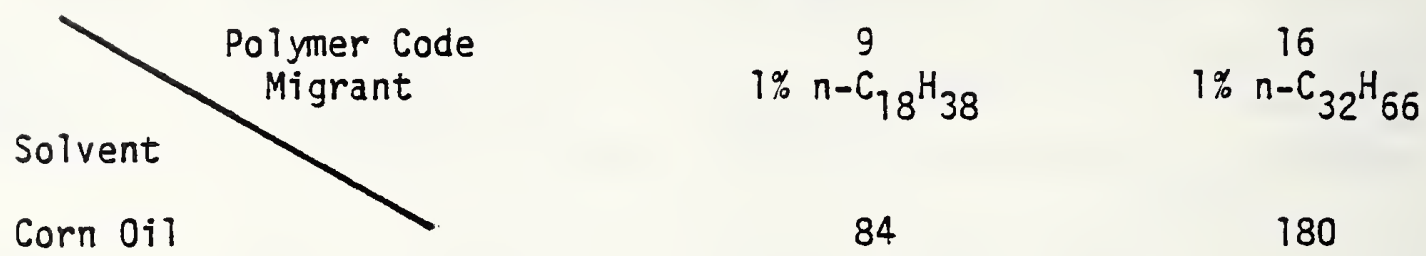

25

Corn Oit

114

180

94

HB307

190

84 


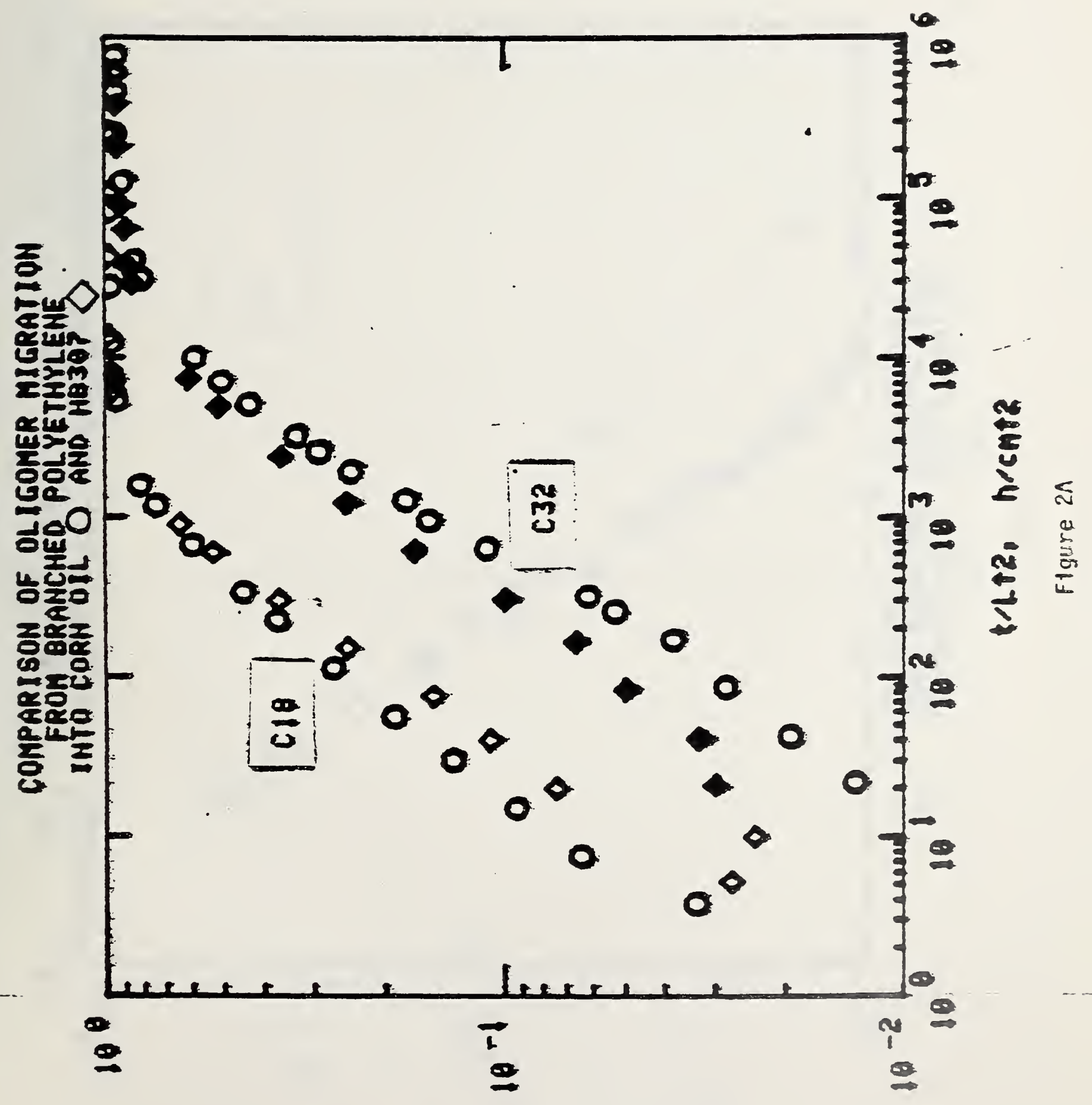

$z-v=0$ 


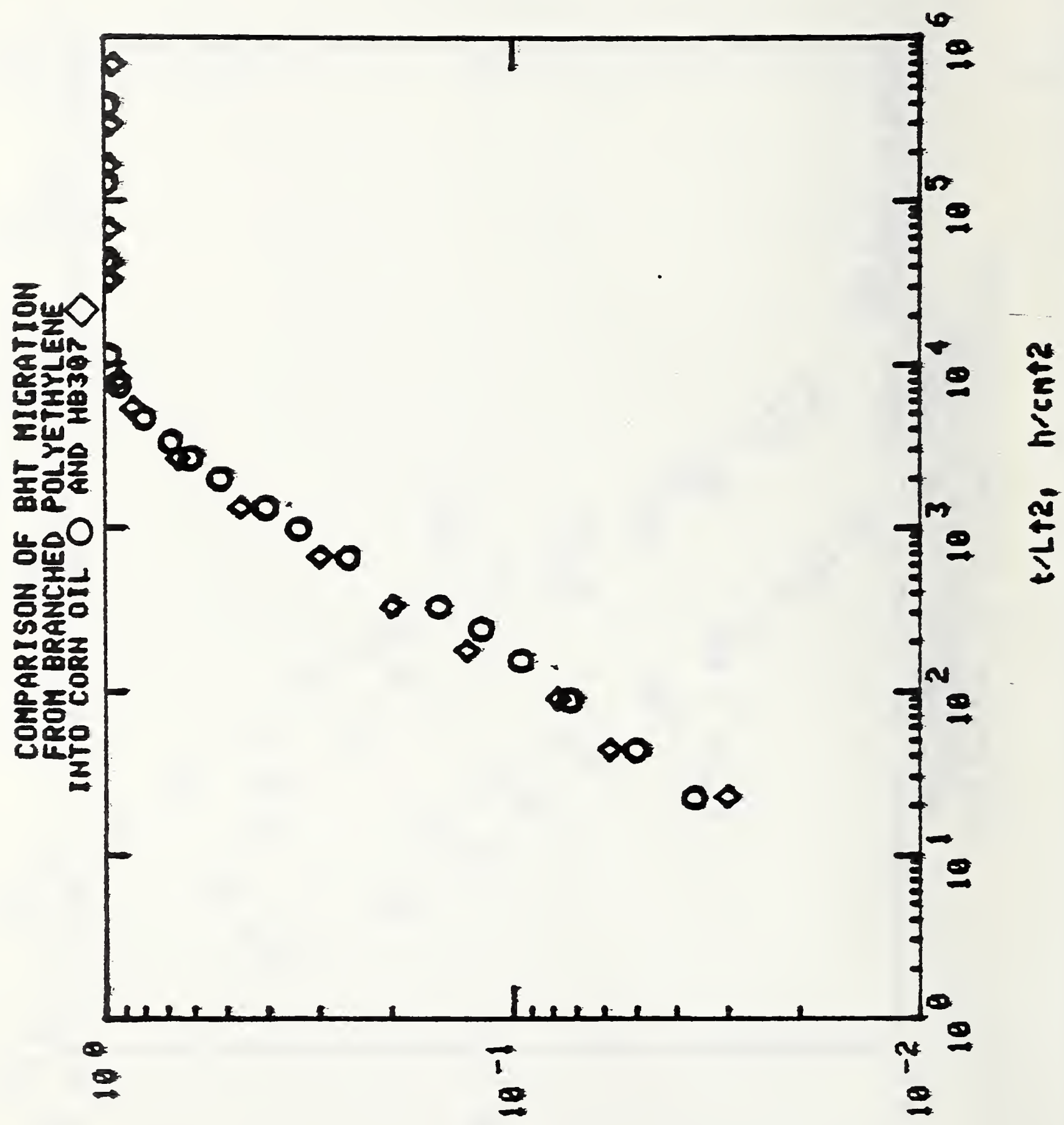

$E+v \Sigma 0$ 


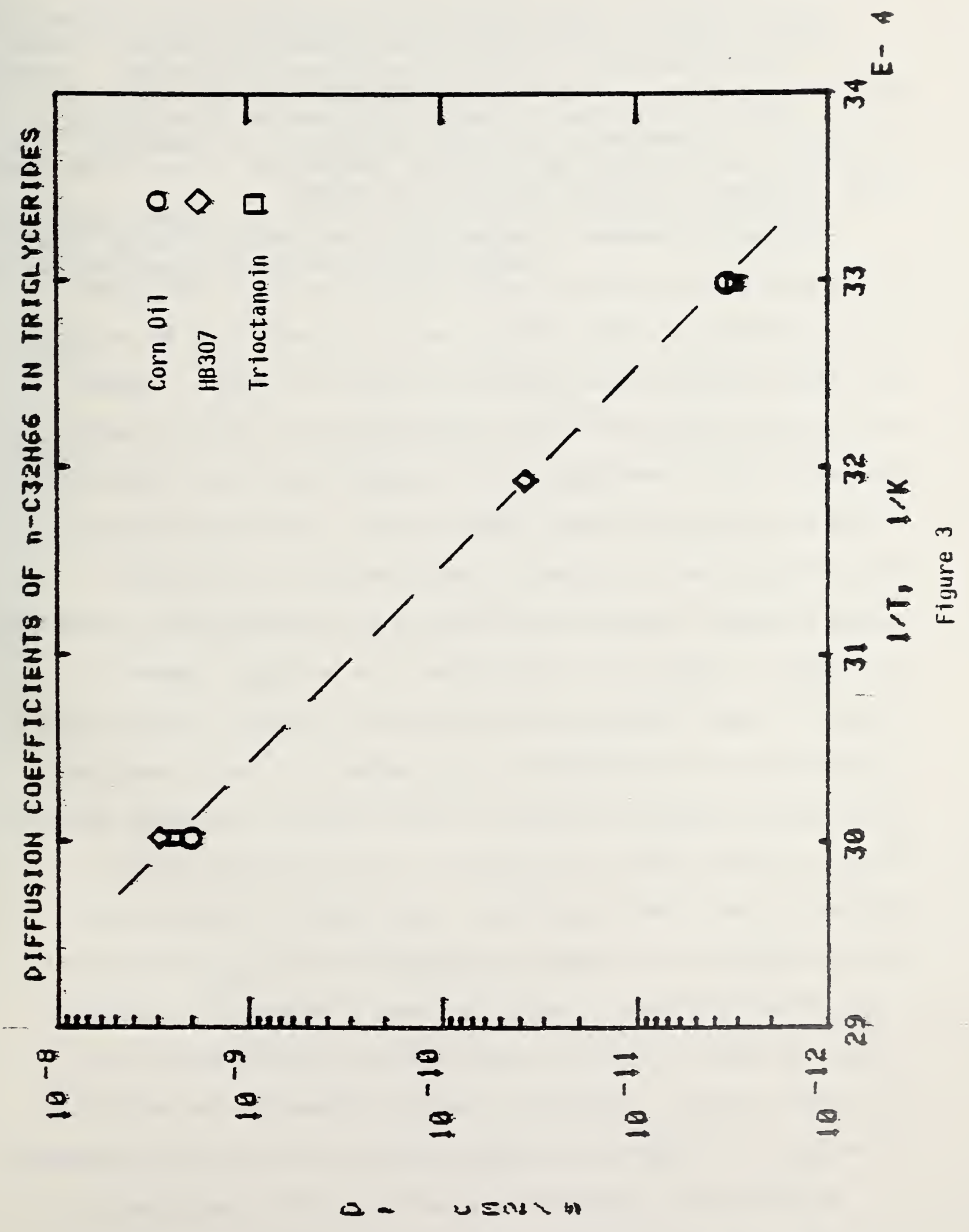




\section{Effect of $5 \%$ Water on Ethanol Extractions}

Anhydrous ethanol left exposed to the atmosphere will absorb moisture and eventualiy reach a constant boiling composition of $95 \%$ ethanol and $5 \%$ water. It is important to assess the influence of this amount of water in ethanol on additive migration into ethanol.

The results presented in Tables 4 and 5 and shown in Figures 4 and 5 indicate that the diffusion coefficients and partition coefficients for the migration of lower molecular weight oligomers, such as $n-C_{18} \mathrm{H}_{38}$, are little affected by the presence of $5 \%$ water in ethanol. However, for $n-C_{32}{ }_{66}$ and BHT the diffusion coefficients are reduced by nearly one-half. This is consistent with the general conclusions in Section VI of the previous annual report, NBSIR 81-2264. Correlations developed there indicate that an increase in the extracting solvent polarity causes a greater reduction in the diffusivity of migrants with a relatively low diffusion coefficient in the polymer (i.e. $n-C_{32}{ }_{66}$ ) compared to those with higher diffusion coefficients (i.e. $n-C_{18} H_{38}$ ). The partition coefficients are also modified by the presence of $5 \%$ water, hence the total level of migrant extractable at equilibrium will be rather different. This is a direct result of the change in the solubilities of these migrants in the solvents considered. Such solubility changes can be rather substantial, for example the solubility of $\mathrm{n}-\mathrm{C}_{18} \mathrm{H}_{38}$ in ethanolwater mixtures decreases by about six orders of magnitude as the water content increases from zero to $100 \%$ (Figure E5 of NBSIR $80-1999$, the FY79 Annual Report). The effect of water in ethanol on the solubility of $n-C_{32} H_{66}$, an extremely hydrophobic migrant, may be even more pronounced. We are currently studying the solubility of the three migrants in $95 \%$ ethanol. The exact value of the solubility of BHT may be somewhat difficult to assess since BHT degrades in solution over the extended 
period of time required for the determination. Nevertheless, we hope to gain information about the relative solubility of BHT in anhydrous and $95 \%$ ethanol. The partition coefficients for BHT in $95 \%$ ethanol are simply an indication of the possible existence of partitioning rather than true values due to the combined effects of BHT decomposition during the extraction process, non-uniform distribution of BHT, and BHT grafted to the polymer sample during the molding process. 


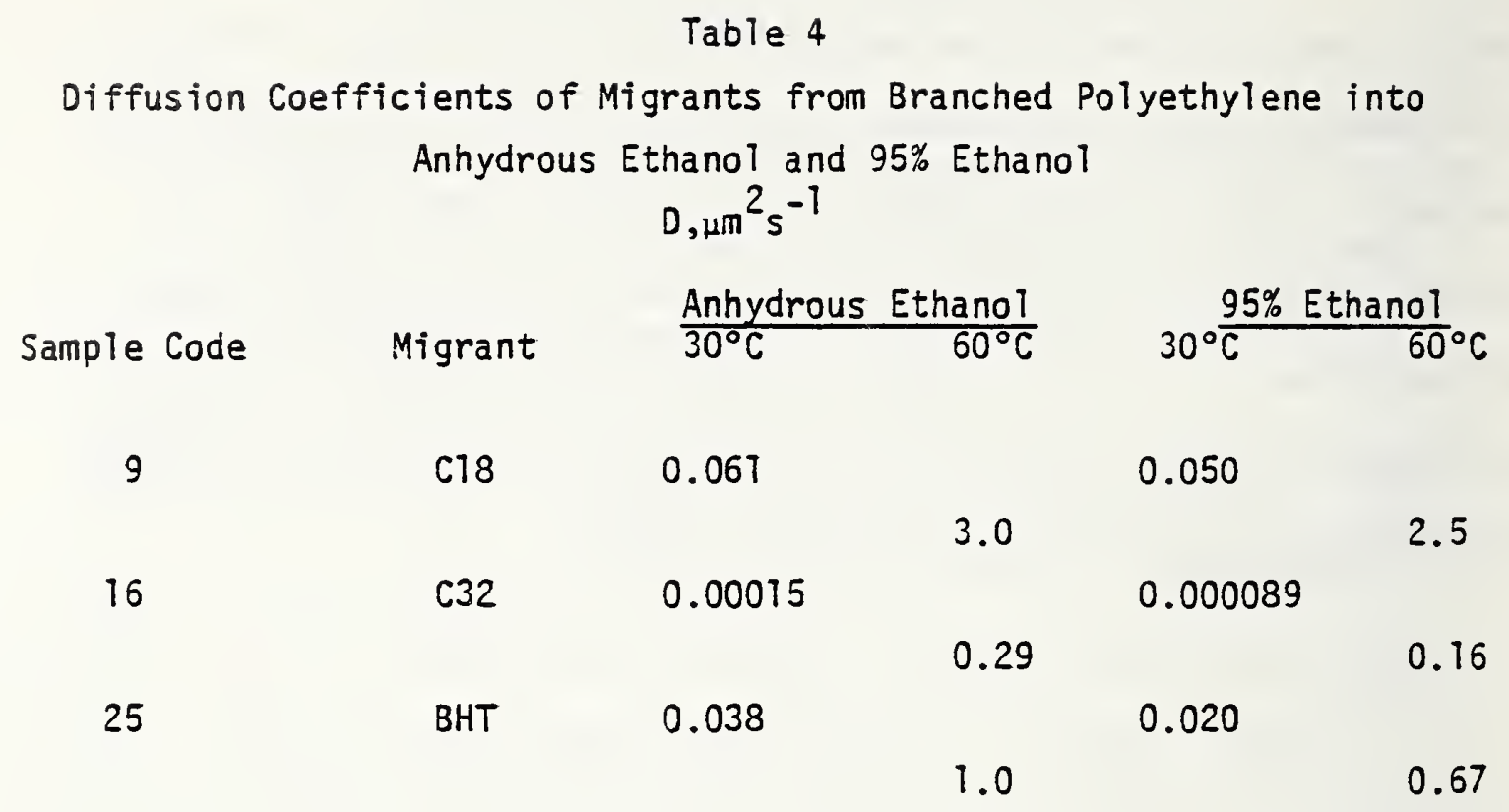




\begin{abstract}
Table 5
Partition Coefficients of Migrants between Anhydrous Ethanol

or $95 \%$ Ethanol and Branched Polyethylene
\end{abstract}

$$
\begin{gathered}
\text { Partition Coefficient } \\
\qquad(k=C s / C p)
\end{gathered}
$$

Migrant
in Branched Polyethylene

$1 \% \mathrm{n}-\mathrm{C}_{78} \mathrm{H}_{38}$

$1 \% \mathrm{n}-\mathrm{C}_{32} \mathrm{H}_{66}$

$0.01 \%$ BHT
Anhydrous

Ethanol

$30^{\circ} \mathrm{C}$

\begin{tabular}{|c|c|c|c|}
\hline \multicolumn{2}{|c|}{$\begin{array}{l}\text { Anhydrous } \\
\text { Ethanol }\end{array}$} & \multicolumn{2}{|c|}{$\begin{array}{c}95 \% \\
\text { Ethanol } \\
\end{array}$} \\
\hline $30^{\circ} \mathrm{C}$ & $60^{\circ} \mathrm{C}$ & $30^{\circ} \mathrm{C}$ & $60^{\circ} \mathrm{C}$ \\
\hline - & & $>0.045$ & \\
\hline & - & & - \\
\hline 0.004 & & $>0.00022$ & \\
\hline & 0.033 & & 0.006 \\
\hline - & & $\sim 0.02$ & \\
\hline & - & & 20.02 \\
\hline
\end{tabular}

$60^{\circ} \mathrm{C}$

$95 \%$

Ethanol

$\sim 0.02$

*For most extractions with 95\% ethanol, the experiments have been carried to near completion but not quite to the point of equilibrium partitioning. The partition coefficient indicated in this colum is therefore the lower-bound vaiue. 


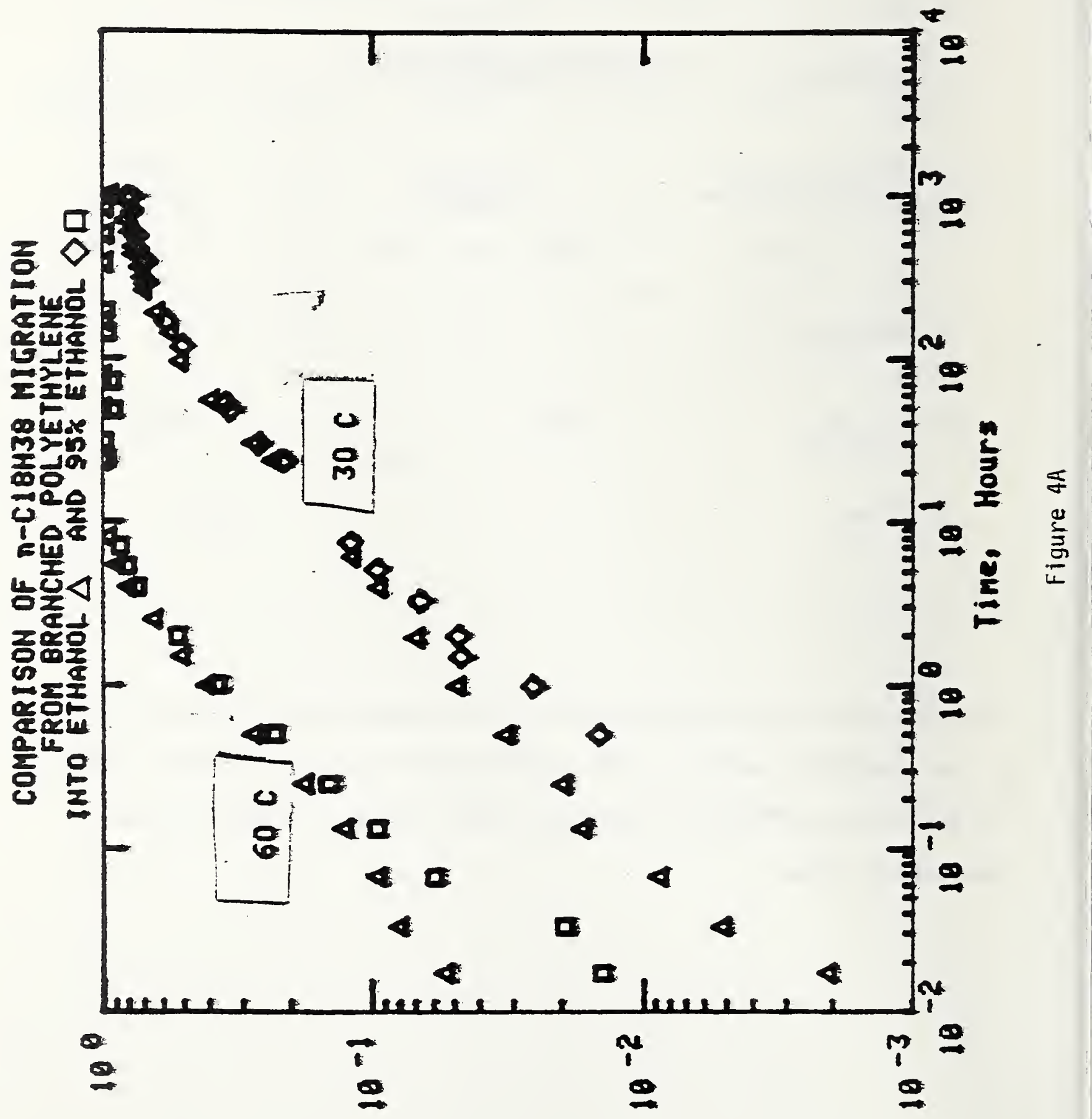




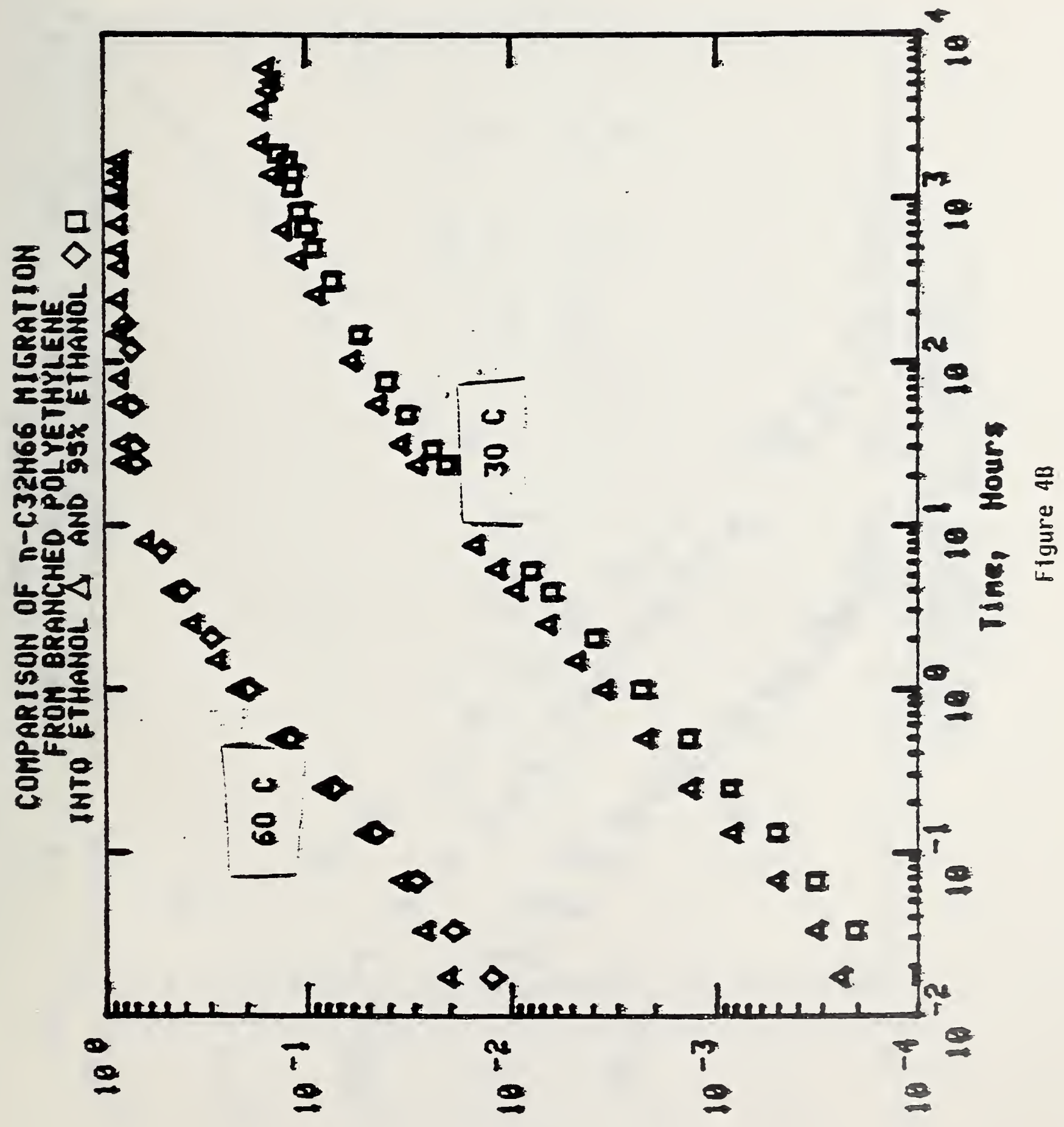




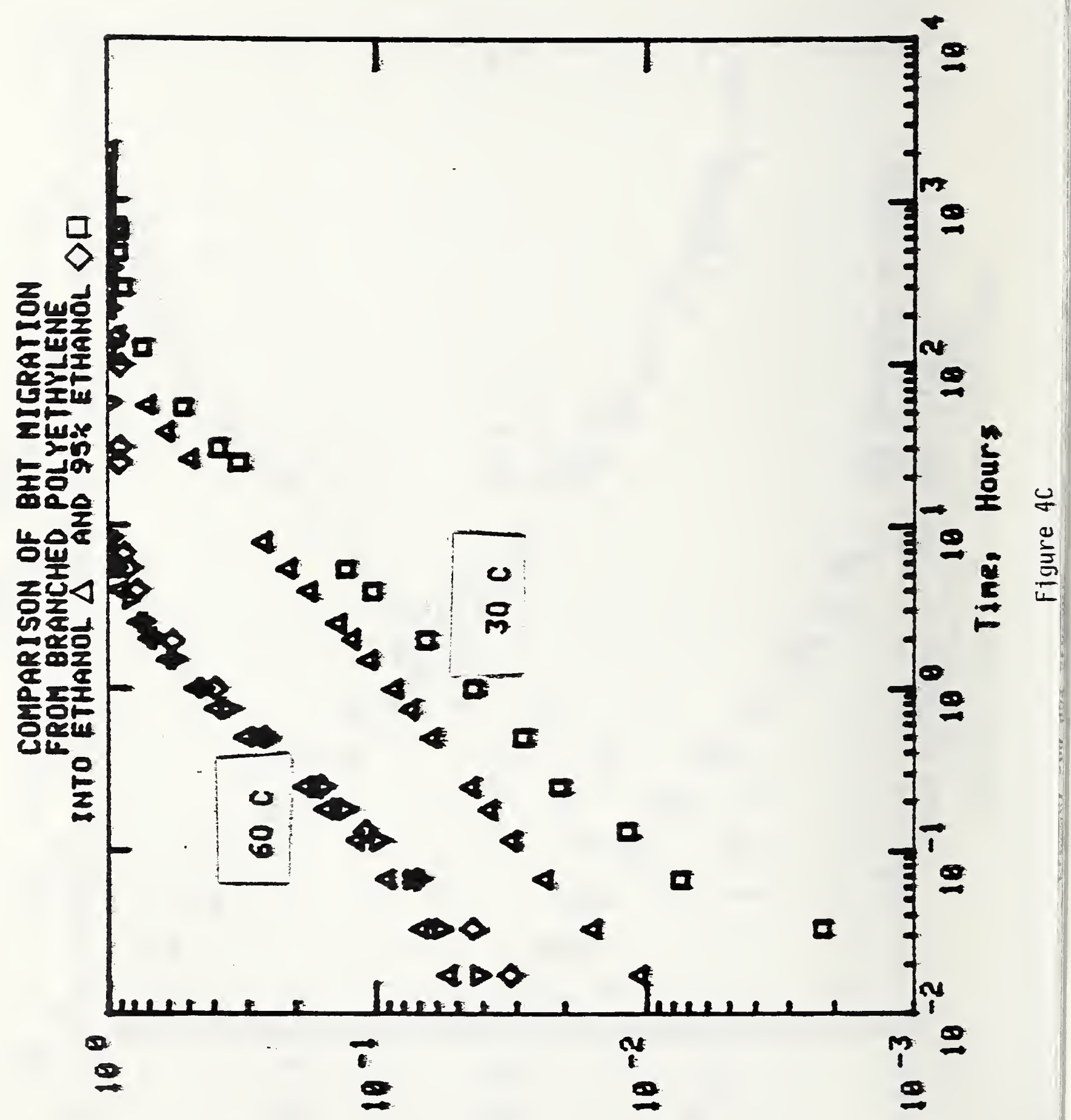

$=+\infty \quad \Sigma 0$ 


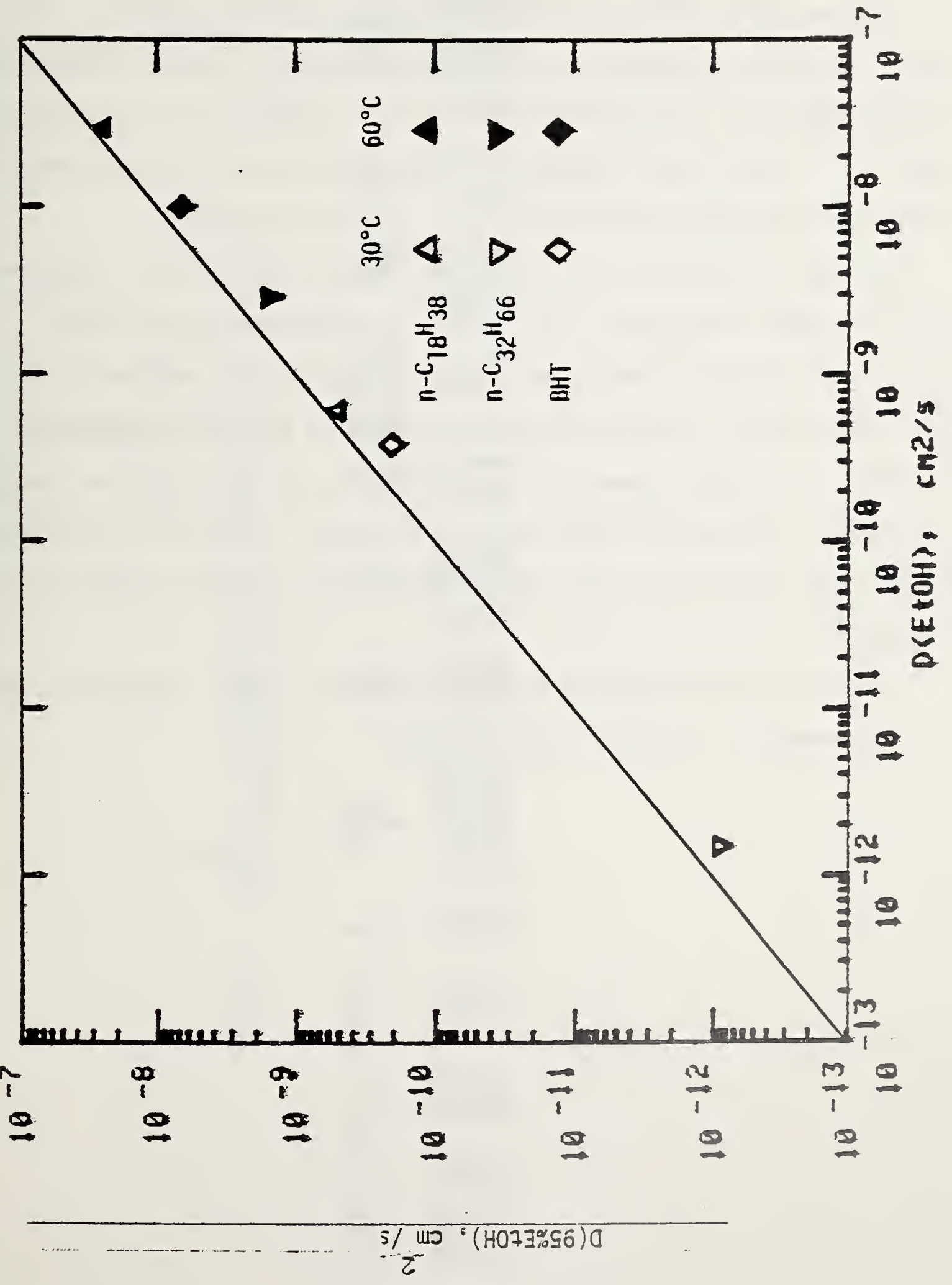




\section{Migration of BHT from Ethylene Vinyl Acetate Copolymers}

Ethylene vinyl acetate copolymer of low vinyl acetate content is being used in increasing quantities as a food contact polymer. We are studying the migration behavior of the antioxidant BHT in this copolymer. The results are summarized in Table 6 and compared with the corresponding migration behavior in branched polyethylene in Figures $6 A, B$, and $C$ and in Table 7.

BHT has a higher mobility in the (ethylene $5 \%$ vinyl acetate) copolymer than in branched polyethylene. The effect is more pronounced at lower values of the diffusion coefficient. For extractions by $n$-heptane there is only a 50\% increase in the diffusion coefficient in E5\%VA when compared to the BPE valve. Ethanol appears to be a stronger accelerating solvent compared to corn oil in the case of E5\%VA (with an increase in the diffusion coefficient of about $50 \%$ ) than for BPE (with an increase in the diffusion coefficient of about $20 \%$ ).

We are currently extending these experiments to lower temperatures and to a copolymer with $13 \%$ vinyl acetate content. 


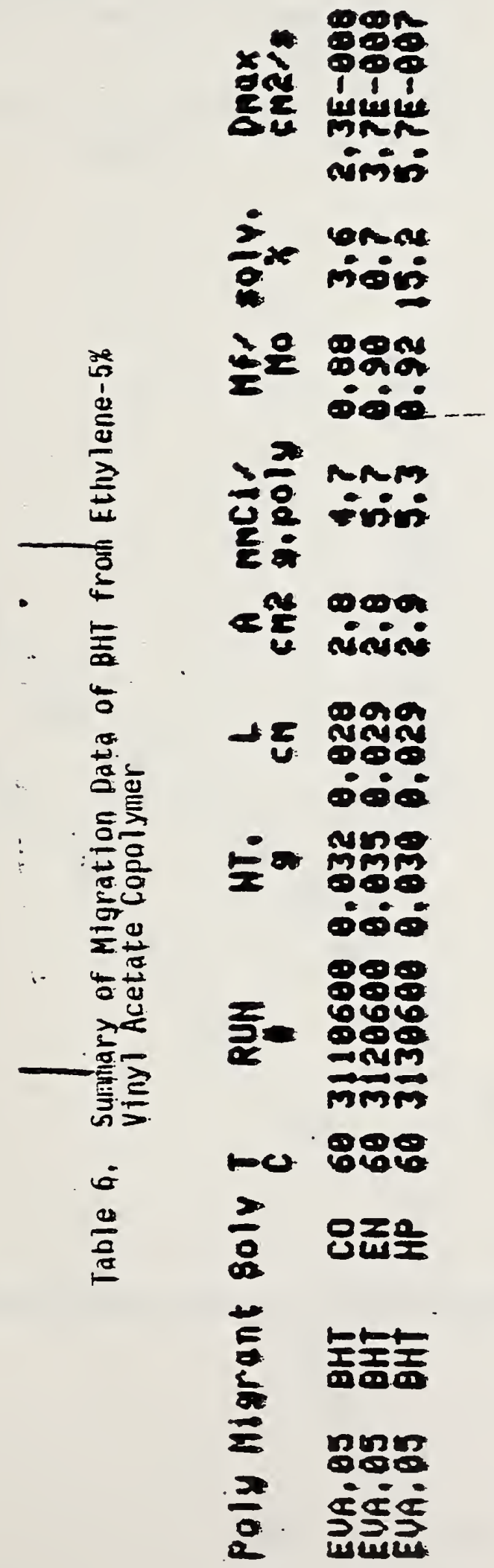




Table 7
Comparison of Migration of BHT from Branched Polyethylene and from
(Ethylene - $5 \%$ Vinyl Acetate) Copolymer at $60^{\circ} \mathrm{C}$
$D, \mu \mathrm{m}^{2} \mathrm{~s}^{-1}$
BPE

Corn $0 i 1$

0.8

2.3

Ethanol

1.0

3.7

n-Heptane

37

57 


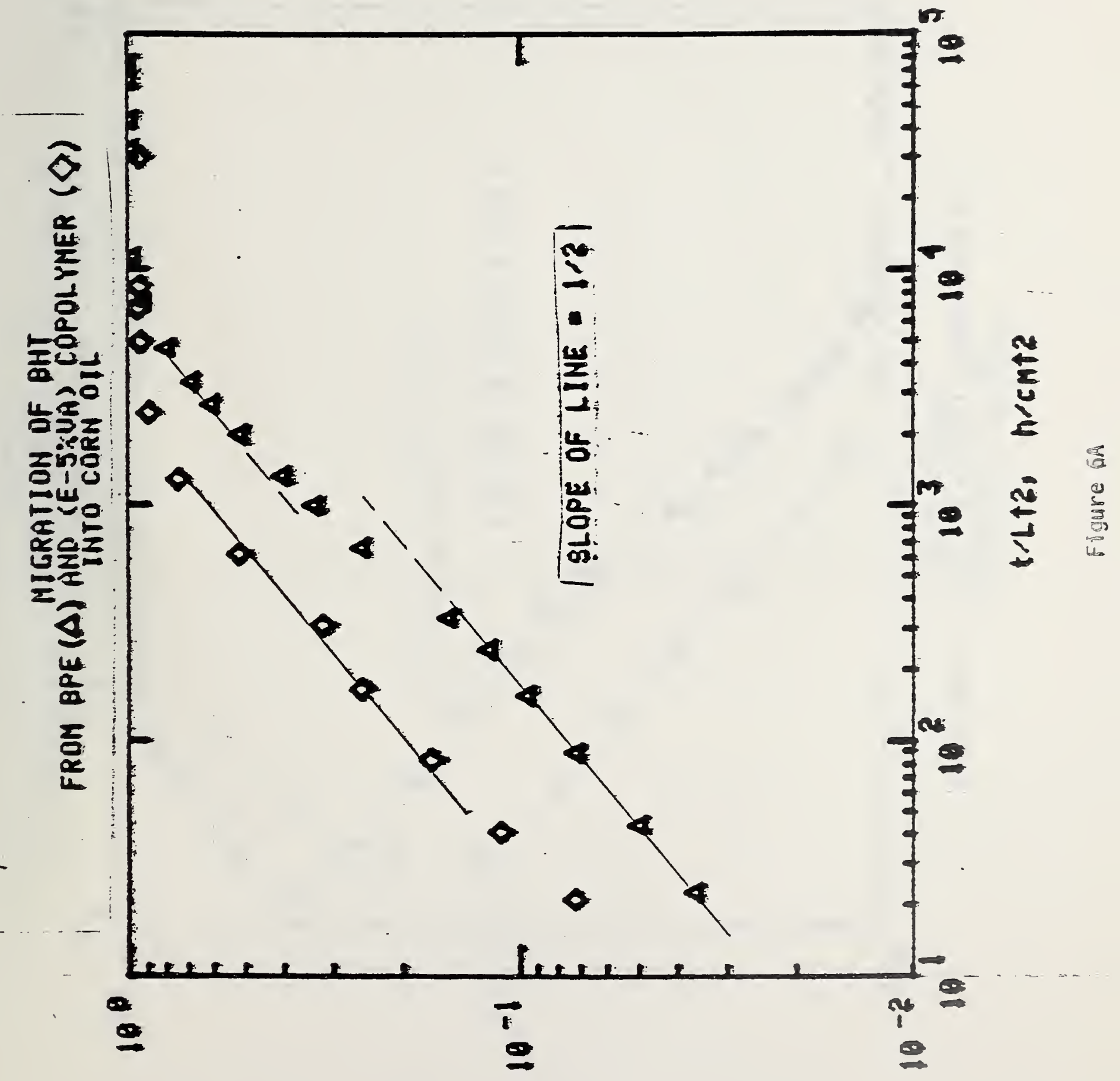

$\sum+\infty>0$ 


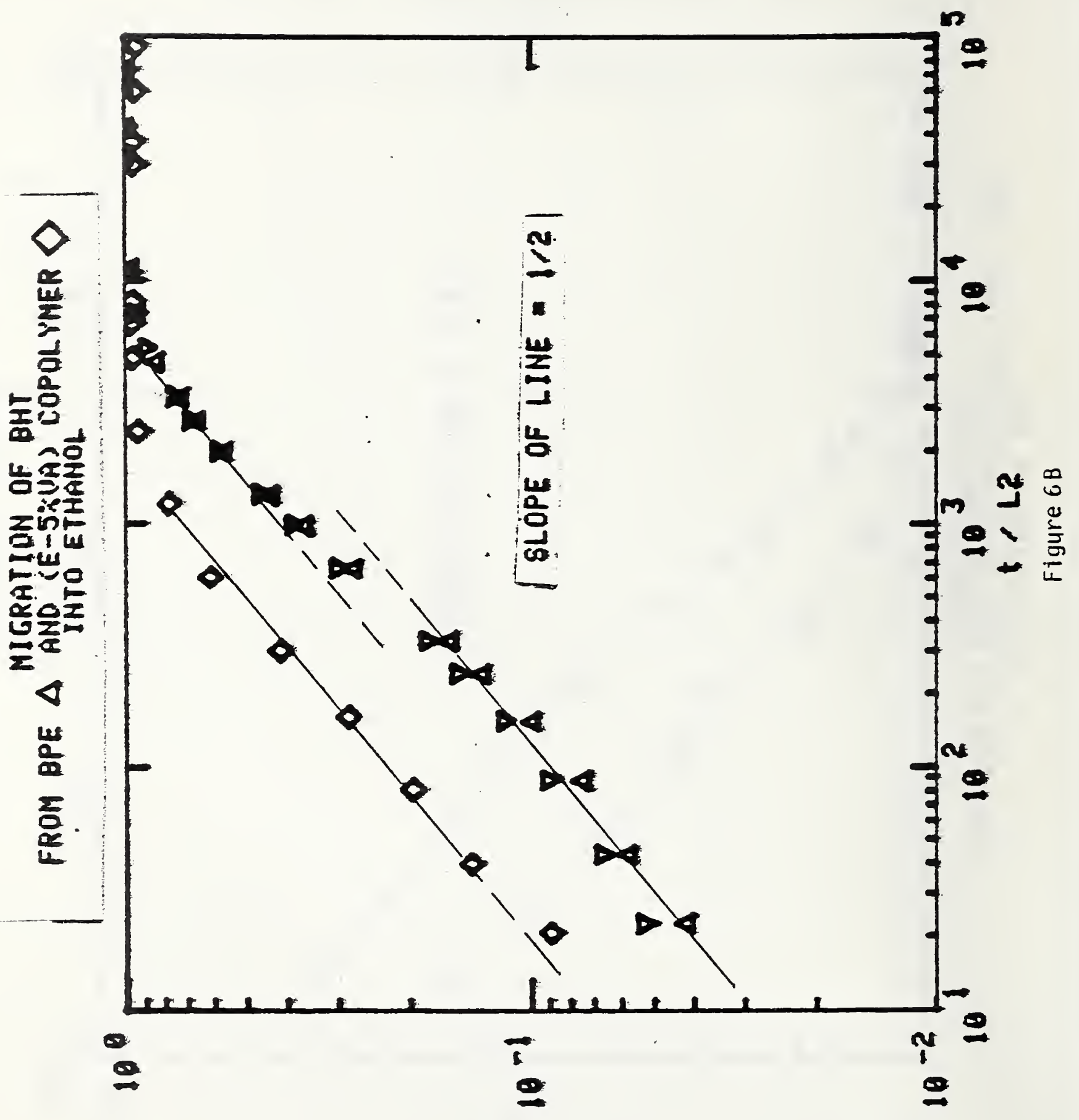

$=+2=0$ 


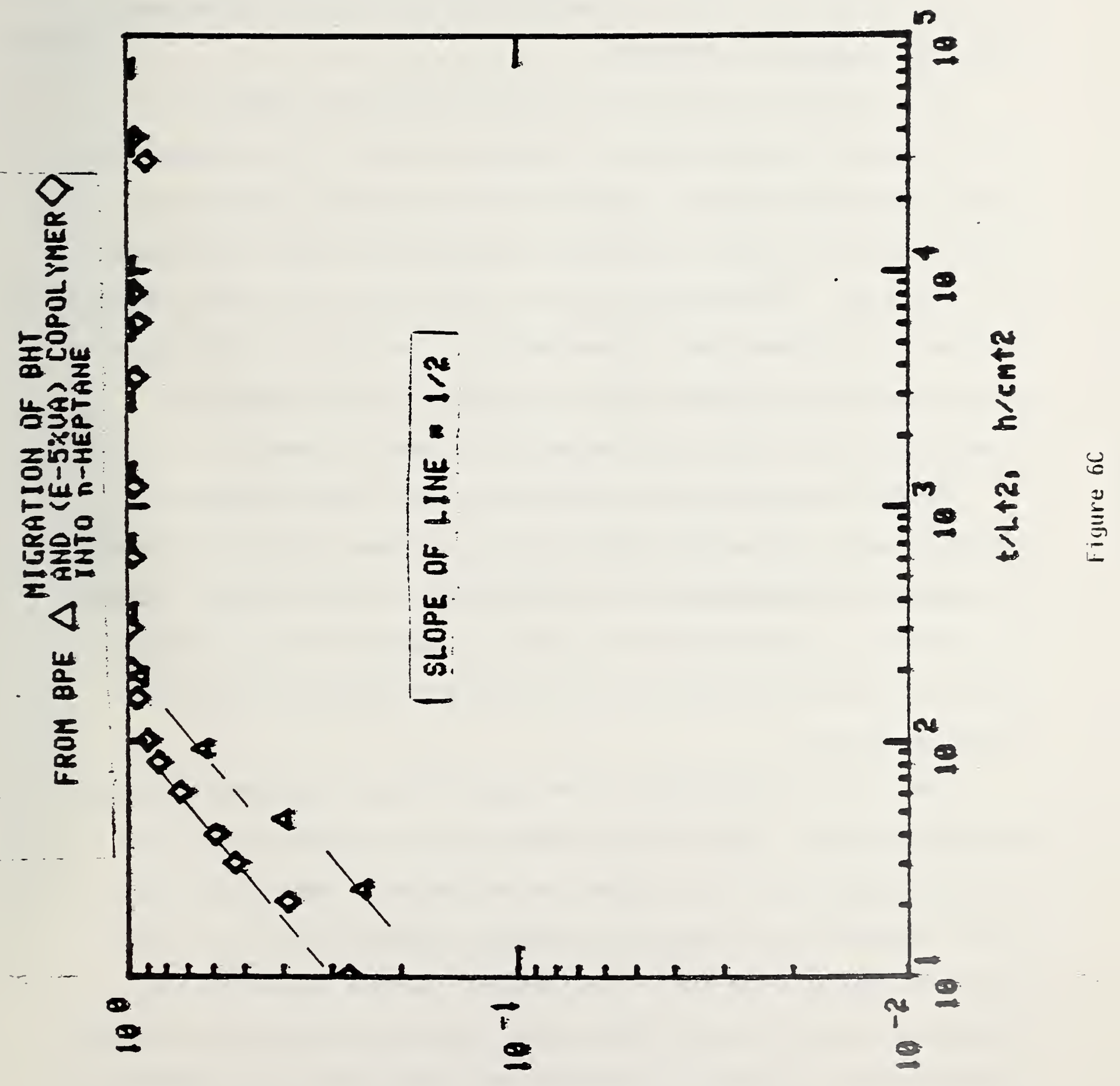

$=+\downarrow \geq 0$ 


\section{Migration of VCM from PVC}

The automatic head-space gas chromatograph, Perkin-Elmer Model F45, arrived in early April and is now awaiting set up and testing by the vendor before our acceptance is finalized.

Our first step will be to establish and calibrate the sensitivity of this instrument by using a series of standard solutions. The purported 2-3 order of magnitude increase in sensitivity of the electron capture detector (ECD) to VCM by the use of carrier gas containing up to 50ppm nitrous oxide will be studied. The ECD sensitivity as a function of nitrous oxide concentration is of major importance since a determination of the kinetics of VCM migration at very low levels is strongly tied to the stability of the sensitivity enhancement in the nitrous oxide concentration range of concern.

Extraction experiments may be performed on both powdered samples and molded plaques. The powdered sample may not yield good kinetic data because the sample is not monodisperse but has a particle size distribution. However, the submicron size particles may be useful for studying the equilibrium or partitioning properties that are very important in determining the final amount of migration.

Kinetic data on VCM migration from glassy PVC may be provided by studying the molded plaques. Relatively high temperatures are needed to mold rigid PVC and decomposition of the polymer can be detected at temperatures above $100^{\circ} \mathrm{C}$. Although the main degradation product is hydrogen chloride, a trace amount of vinyl chloride may also be produced. We hope to overcome this problem by analyzing the total VCM content in the plaque before the extraction experiment and by studying or minimizing the effect of $\mathrm{HCl}$ on the determination of VCM. 
We expect to have completed sufficient preliminary studies in this fiscal year to enable us to assess the reliability of the low level VCM migration studies. 
IV. Review of the Migration of Organotin Compounds from PVC

Incorporation of a heat stabilizing material into poly(vinyl chloride) is necessary in order to limit thermal degradation and prevent discoloration at the high temperatures at which the PVC melt must be processed. These stabilizers are thought to react with $\mathrm{HCl}$ evolved from the polymer and prevent it from causing further degradation. The chemical reaction mechanisms underlying the stabilizing ability of the organotins in PVC have been reviewed in detail elsewhere (Ayrey and Poller, 1980). Another recent review on the performance of tin stabilizers under actual processing conditions is available (Cooray and Scott, 1980).

Two organotin stabilizers have been approved by FDA (Food and Food Products Regulations $121.2602,1 / 20 / 68$ and $178.2650,1 / 16 / 75$ ) for food packaging applications, di-n-octyltin-bis(2-ethylhexyl thioglycolate) (I), and di-noctyltin maleate polymer (II). These stabilizers, but primarily I, have been the subjects of numerous migration studies, with both foods and food simulants used as the extracting medium for stabilized, rigid PVC. Long term migration studies of I from PVC bottles into liquid foods have been conducted (Carr, 1969) and the concentration extracted after two months at $30^{\circ} \mathrm{C}$ given. The quantity of tin extracted from the bottles as organotin was often found to be comparable to the amount of "natural tin" or the background level of tin in the foods before extraction, indicating the importance of taking this factor into account to correct experimental total tin determinations. After six months, the amount of I migrating from PVC bottles into sunflower oil was found to be less than or equal to $2 \mathrm{ppm}$ (Woggon et al., 1969). Beer stored in PVC bottles at $20^{\circ} \mathrm{C}$ for eight months contained $0.01 \mathrm{mg} \mathrm{I} / 1$ (Koch and Figge, 1971). Organotin stabilizers were readily extracted from PVC food containers by olive oil, orange or lemon soft drink concentrate, and aqueous ethanol (Brighton, 1968). Migration of I and II into a variety of liquid 
foods has been studied at $57^{\circ} \mathrm{C}$ for eight weeks (Pinkasavage, 1970). Levels of organotins in these materials ranged from $0.01-0.24 \mu \mathrm{g}$ organotin/g food. No additional changes in the level of migration were found when the study was extended at room temperature to a full year in duration.

Several studies have been conducted with food simulating solvents as the extracting medium. A brief review on the use of food simulating solvents in determining migration of dioctyltin stabilizers from PVC is available (Keller et al., 1975). Impact resistant PVC containing about 1\% I was extracted with seven simulants (Dosta1, 1980). The stabilizer was eluted over the range $0.004-0.045 \mathrm{mg} / \mathrm{dm}^{2}$ polymer, the latter value for extraction with heptane. Studies of extraction kinetics comparing liquid foods to their corresponding simulating solvents have been reported (Keller et al., 1974). The total amount of stabilizer extracted varied from $0.06 \mathrm{\mu g} \mathrm{I} / \mathrm{g}$ for type II foods to $0.44 \mathrm{\mu g} \mathrm{I} / \mathrm{g}$ for type $V$ foods. Stabilizer I could be readily detected in heptane and other organic solvents used to extract rigid PVC but could not be detected in coconut oil, triacetin, or triglyceride mixtures (Bergner and Berg, 1972). Radiolabeled stabitizers have also been studied. A determination of the total amount of all components migrating, so-called "global migration", has been made for rigid PVC stabilized with I (Figge, 1976). The fat simulant HB307- ${ }^{14} \mathrm{C}$ was used in these extractions. The total quantity of migrants extracted is equal to the weight lost by the polymer during storage in the simulant after correcting for the amount of simuiant absorbed. The radiolabeled stabilizers methyltin-tri-(III), dimethyltin-di-(IV), and trimethyltinthioglycolic acid-2-ethylhexyl ester $(V),{ }^{14} C$-iabeled in both the methyltin or thioglycolate moiety, have been extracted with $4 B 307$ (Figge, 1975). ine total amount of intact stabilizer migrating into fat-containing foods ivas found to be $<1 \mathrm{ng} I I / \mathrm{g}, 73 \mathrm{ng} I V / g$, and $39 \mathrm{ng} \mathrm{V} / \mathrm{g}$.

Typical food-grade PVC formulations include not oniy a stabitizer but also processing aids, lubricants, and coiorants. Imoact modifiers and plasticizers are often added. These materials can each be present at ievels of $T-10 \%$ by 
weight of the total molding compound. The influence of these additional components on stabilizer migration has been studied by several investigators. The chemical nature of organotin stabilizers was reported to have little effect on their migration from compounded PVC into water (Sheftel, 1978). The migration of dibutyitin-bis(isoctyl thioglycolate) (VI) stabilizer into water was found to increase as stabilizer and plasticizer (dioctyl phthalate) content increased. A study on the influence of epoxidized soybean oil, a lubricant, on the migration of dioctyltin and dibutyltin compounds into $50 \%$ ethanol, $5 \%$ acetic acid, and sunflower $0 i 1$ at $45^{\circ} \mathrm{C}$ for ten days concluded that lubricant concentrations below $3 \%$ have no effect on stabilizer migration (Woggon et al., 1967). Giobal migration from rigid PVC into water, 10\% aqueous ethanol, and $3 \%$ acetic acid was found to be unafiected by the presence of up to $11 \%$ of this lubricant or by the addition of I (Thomas, 1980).

Detection of tin in foods is typically accomplished by oxidative destruction of the food with a nitric and sulfuric acid mixture followed by addition of $\mathrm{HBr}$ and $\mathrm{HCl}$ to form a tin halide which is then distilled and its concentration determined quantitatively by colorimetry. The distillation step can be omitted when food simulants are used. The method is sensitive to $5-7 \mu g \mathrm{tin}$, depending on whether dithiol or pyrocatechol violet is used as the reagent in colorimetric determinations. An anodic stripping method for determination of organotin compounds has also been described and an analytical scheme proposed for detection of these compounds and their decomposition products migrating from PVC (Woggon, et a1. 1972). Radiolabeled stabitizer compounds have been used successfully as a sensitive method for quantifying migration, as discussed previously. Flameless atomic absorption spectroscopy (AA) has also been used in a recent study of organotins extracted from PVC by water and edible oils (Taleb et al., 1979). The water extracts were injected directiy while the oil samples required dilution with cyclohexane. The limit of detection was reported to be $1.8 \mathrm{jg} \mathrm{Sn} / \mathrm{g}$ in PVC and approximately $10 \mathrm{ng} \mathrm{Sn} / \mathrm{g}$ in the simulants. 
AA has been employed to detect octyltins extracted by water from PVC pipe (Dietz et al., 1979). Their quantitative analysis of tin was complicated by adsorption of extracted tin and precipitation of insoluble tin compounds. The procedure was modified by acidifying the solutions with concentrated $\mathrm{HCl}$ before AA analysis, which increased the tin level in solution by a factor of eight.

There is a lack of a consensus in the organotin migration literature on two issues: whether the whole stabilizers or their degradation products migrate into simulating solvents and the source of the stabilizer available for extraction. On the question of stabilizer degradation, the undegraded organotin compound was found to migrate from PVC into hexane and lipid based extractants while the major component migrating into aqueous extractants was an organotin oxide in the form of the cyclic trimer, $\left(\mathrm{R}_{2} \mathrm{SnO}\right)_{3}$, with minor amounts of the undegraded compound and an al cohol form, $\mathrm{R}_{2} \mathrm{Sn}(\mathrm{OH})_{2}$, also thought to be present (Yen, 1970). Migration of di-n-octyltin esters and other organotins into aqueous and fatty foods has been studied (Woggon, et a1. 1971). No chemical change in the octyltins was evident while for the other organotins studied mainly decomposition products were found to have been extracted. Experiments with I, radiolabeled at the ester or n-octyl group, migrating into edible oils showed that the stabilizer migrates either undegraded from rigid. PVC or, following its hydrolysis, into two moieties which migrate at the same rate (Seidler et. al., 1971). The same material similarly radiolabeled has been the object of another study involving migration into edible oils and HB3OT (Figge and Zeman, 1973). They concluded that the stabilizer and its decomposition products di-n-octyltin dichloride (VII) and oxide (VIII), 2-ethylhexyl thioglycolate (IX), and their decomposition products al1 migrate from PVC into fat-containing foods. In addition, free VIII was thought to form cyclic trimer and migrate into aqueous media. Further studies with this radiolabeled stabilizer (Figge et al., 1979) showed that it did not 
migrate intact but VII and bis(2-ethylhexyloxycarbonyimethyl) disulfide $(X)$, the dimer of $I X$, could be found in small amounts in aqueous or fat simulants. The quantities migrating (in $\mu \mathrm{g} / \mathrm{dm}^{2}$ polymer) for ten days at $40^{\circ} \mathrm{C}$ were given as follows: 0.04-0.17 VII and 0.14-0.47 X into water and 3\% acetic acid, 0.50-2.12 VII and 0.51-0.99X into HB307 and 01 ive 011 , and 0.88-5.48 VII and 3.63-3.81 X into heptane. If the stabilizers II, III, and IV discussed previously were transformed into the corresponding methyltin chlorides and thioglycolates before or during migration, their concentration in fatcontaining foods has been determined to be $0.5,29$, and $13 \mathrm{ng} / \mathrm{g}$ for the methyltin chiorides of I I through IV, respectively (Figge, 1975). No definite conclusions can be drawn on the chemical nature of the migrating species of stabilizer I from the available literature.

Several studies present evidence that organotin stabilizers are extracted primarily from the surface of rigid PVC and not from bulk polymer as is normally assumed. A rapid initial migration into heptane and $95 \%$ ethanol followed by a period of further migration at a decreased rate was evident for samples containing $2 \%$ stabilizer (Downes and Gilbert, 1975, Downes, 1972). The initial amount of migration was greatly retarded when the PVC surface was cleaned with heptane prior to extraction. If the polymer was aged for two weeks following the surface cleaning, the retardation of migration was no longer observed upon extraction. A study on migration of decomposition products of I into edible oils and HB307 described previously concluded that since PVC cannot be swelled by these liquids, stabilizers within the polymer cannot migrate from the samples and only free surface stabilizer is available for extraction (Figge and Zeman, 1973). This point was amplified in a later study (Figge et al., 1979). Stabilizer I, some IX, and a trace of $X$ could be found in the bulk polymer while only decomposition products VII and $X$ could be identified on its surface. The latter two compounds were the species determined to have been extracted by the simulating solvents. These PVC 
adsorption of extracted tin and precipitation of insoluble tin compounds. The procedure was modified by acidifying the solutions with concentrated HCT before $A A$ analysis, which increased the tin level in solution by a factor of eight.

There is a lack of a consensus in the organotin migration literature on two issues: whether the whole stabilizers or their degradation products migrate into simulating solvents and the source of the stabilizer available for extraction. On the question of stabilizer degradation, the undegraded organotin compound was found to migrate from PVC into hexane and lipid based extractants while the major component migrating into aqueous extractants was an organotin oxide in the form of the cyclic trimer, $\left(R_{2} S n O\right)_{3}$, with minor amounts of the undegraded compound and an alcohol form, $R_{2} S n(O H)_{2}$, also thought to be present (Yen, 1970). Migration of di-n-octyitin esters and other organotins into aqueous and fatty foods has been studied (Woggon, et al. 197.7). No chemical change in the octyltins was evident while for the other organotins studied mainly decomposition products were found to have been extracted. Experiments with I, radiolabeled at the ester or n-octyl group, migrating into edible oils showed that the stabilizer migrates either undegraded from rigid PVC or, following its hydrolysis, into two moieties which migrate at the same rate (Seidler et. al., 1971). The same material similarly radiolabeled has been the object of another study involving migration into edible oils and HB307 (Figge and Zeman, 1973). They concluded that the stabilizer and its decomposition products di-n-octyltin dichioride (VII) and oxide (VIII), 2ethylhexyl thioglycolate (IX), and their decomposition products all migrate from PVC into fat-containing foods. In addition, free VIII was thought to form cyclic trimer and migrate into aqueous media. Further studies with this radiolabeled stabilizer (Figge et al., 1979) showed that it did not migrate intact but VII and bis(2-ethyihexyloxycarbonylmethyI)disulfide $(X)$, the dimer 
of IX, could be found in small amounts in aqueous or fat simulants. The quantities migrating (in $\mu \mathrm{g} / \mathrm{dm}^{2}$ polymer) for ten days at $40^{\circ} \mathrm{C}$ were given as follows: 0.04-0.17 VII and 0.14-0.47 X into water and 3\% acetic acid, 0.502.12 VII and 0.51-0.99 X into HB307 and olive 0il, and 0.88-5.48 VII and 3.63-3.81 $x$ into heptane. If the stabilizers II, III, and IV discussed previously were transformed into the corresponding methyltin chlorides and thiogiycolates before or during migration, their concentration in fatcontaining foods has been determined to be $0.5,29$, and $13 \mathrm{ng} / \mathrm{g}$ for the methyltin chlorides of II through IV, respectively (Figge, 1975). No definite conclusions can be drawn on the chemical nature of the migrating species of stabilizer I from the available literature.

Several studies present evidence that organotin stabilizers are extracted primarily from the surface of rigid PVC and not from bulk polymer as is normally assumed. A rapid initial migration into heptane and $95 \%$ ethanol followed by a period of further migration at a decreased rate was evident for samples containing 2\% stabilizer (Downes and Gilbert, 1975, Downes, 1972). The initial amount of migration was greatly retarded when the PVC surface was cleaned with heptane prior to extraction. If the polymer was aged for two weeks following the surface cleaning, the retardation of migration was no longer observed upon extraction. A study on migration of decomposition products of I into edible oils and $4 B 307$ described previousiy conciuded that since PVC cannot be swelled by these liquids, stabilizers within the polymer cannot migrate from the samples and only free surface stabilizer is available for extraction (Figge and Zeman, 1973). This point was amplified in a later study (Figge et a T., 1979). Stabilizer I, some IX, and a trace of $X$ could be found in the bulk polymer while only decomposition products VII and $X$ could be identified on its surface. The latter two compounds were the species determined to have been extracted by the simulating soivents. These PVC 
samples also showed a maximum amount of migration in the first aliquot of extracting solvent during long term extractions at $40^{\circ} \mathrm{C}$ with both $\mathrm{HB} 307$ and water. An additional complication could arise if some of the stabilizer, either on the surface or in the bulk material, is not free to migrate but has reacted with polymer molecules during melt processing of the material and become chemically bound to the PVC. This possibility has been mentioned previously but not thoroughly explored. 
1. Ayrey, G.; Poller, R. C., "Organotin Stabilizers for Polyvinyl Chloride", In "Developments in Polymer Stabilization - 2", G. Scott, Ed., Applied Science Publishers Ltd., London, 1980, pp. 1-52.

2. Bergner, K. G.; Berg, H., "Migration of Additives from Plastics in Triglycerides Compared with Their Extractibility by Organic Solvents" Deut. Lebensm. Rundsch. , 68, 2828, 1972. (German) CA77163112

3. Brighton, C. A., "Extractability of Additives from PVC Compounds" Plast. Polym., 36, 54954, 1968. CA7097679

4. Carr, H. G., "Interaction Between PVC Bottles and Liquid Foods" Soc. Plast. Eng. J., 25 (10), 724, 1969. CA7241901

5. Carr, H. G., "Analytical and Other Changes in Liquid Foods Packed in OctyltinStabilized PVC Bottles", Soc. Plast. Eng., Tech. Pap., $15,2437,1969$. $\overline{C A} 71122465$

6. Cooray, B. B.; Scott, G., "The Role of Tin Stabilizers on the Processing and Service Performance of PVC", In "Developments in Polymer Stabilization 2", G. Scott, Ed., Applied Science Publishers Ltd., London, 1980, pp. 53-88.

7. Dietz, G. R.; Banzer, J. D.; Miller, E. M., "Water Extraction of Additives from PVC Pipe", J. Vinyl Technol., I, 1613, 1979. CA93221442

8. Dostal, H., "Extractibility of Stabilizer Sn 831 from PVC into Model Liquids", Cesk. Hyg., 25, 2832, 1980. (Slovak) CA9324604

9. Downes, T. W.; Gilbert, S. G., "Effect of Surface Treatments on the Migration of Organotin Stabilizer from PVC Films to Contacting Liquid Media", Dtsch. Lebensm.Rundsch., 71, 4225, 1975. CA8460365

10. Downes, T. W., "Mechanism of the Migration of Organotin Stabilizer from PVC into Contacting Media", State Uriv. New Jersey, New Brunswick, N. J., Dissertation, 1972.

CA78125073 (Diss. Abstr. Int. B 1973, 33 (8), 3702)

11. Figge, K.; Freytag, W.; Bieber, W. D., "Migration of Decomposition Products of an noctyltin Stabilizer from Different Rigid PVC Types into Food Models", Dtsch. Lebensm.Rundsch., 75, 33345, 1979. (German) CA92109249 
12. Figge, K., "Radioanalytic Method for Determining the Passage of Packing Ingredients into Foods", J. Radioanal. Chem., 32, 315-43, 1976. (German) CA85-121891

13. Figge, K., "Migration of Methyltin Thioglycolic Acid Esters from Rigid PVC Packagings into Fat-Containing Foods", Verpack-Rundsch, $28(8), 59-63,1975$. (German) $\mathrm{CA} 84-15753$

14. Figge, K.; Zeman, A., "Migration of Tin Stabilizers from Unplasticized PVC Film into Fat-Containing Foods. X-ray Photoelectron-Spectroscopic and Radioanalytical Examination of PVC Surfaces", Kunststoffe, $63,543-50,1973$. (German) $\mathrm{CA} 80-13741$

15. Keller, A. A.; Sheldon, A. W.; Simmons, I. L., "Fast Extraction Tests for Food-Grade PVC", Mod. Packag., 48 (8), 42-4, 1975. CA83-176739

16. Keller, A. A.; Sheldon, A. W.; Simmons, I. L., "Accelerated Extraction Tests for Food-Grade Octyltin Stabilized PVC", Soc. Plast. Eng., Tech. Pap., 20, 514-17, 1974. CA81-134681

17. Koch, J.; Figge, K., "Migration of Tin Stabilizers from PVC Bottles into Beer", Z. Lebensm.-Unters.-Forsch., 147, 8-10, 1971. (German) CA75-139.38T

18. Pinkasavage, W. $P$., "Federal Regulatory Requirements for OctyltinStabilized PVC in Food Packaging.", Soc. Plast. Eng., Tech. Pap., Reg. Tech. Conf., Pal isades Sect., (Oct. 27-28), 6 pp., 1970. CA74-75378

19. Seidier, H.; Haertig, H4; Woggon, H.; Uhde, W.-J., "Examinations on the Migration of $(1-4) C$-2-Ethyl-Hexyl Ester of Di-n-Octy 1 Tin Dithioglycolic Acid (Stabilizer OTS 15) From Hard PVC into Edible 0i1", Nahrung, 15, 187-90, 1971. (German) CA75- 128128

20. Sheftel, V. O., "Effect of the Chemical Composition of Plastics on the Migration Rate of Their Components into Liquid Media", PTast. Massy, $8,67-3,1978$. (Russian) CA89-164323

21. Sneftel, V. 0., "Permissible Levels of Migration of Some Organotin Stabilizers in PVC", Gigiena Primeneniya Polimer. Materialov, 36-8, 1976. (Russian) CA87-24130 (Ref. Zh., Khim. 1977, Abstr. No. 71660)

22. Taleb, F.; Carrier, M.; Valion, J. J., "Atomic Absorption Spectrometry Study of Food Contamination by Organotin Stabilizers from Food Packages", Ann. Fals. Exp. Chim., 72, 447-54, 1979. (French) CA92-92808 
23. Thomas, G., "Dependence of Migration on the Presence of Epoxidized Soybean 0 il in Unplasticized PVC", Kunststoffe, 70, 161-3, 1980. (German) CA92-216113

24. Woggon, H.; Saeuberlich, H.; Unde, W.-J., "Determination of Organotin Compounds and Their Degradation and Decomposition Products by Anodic Stripping", Z. Ana 1. Chem., 260, 268-74, 1972. (German) CA77-134884

25. Woggon, H.; Unde, W.-J.; Saeuberlich, H., "New Results on the Migration of Organotin Stabilizers in Food", Ernaehrungsforschung, 16, $645-55,1971$. (German) CA78-96769

26. Woggen, H.; Jehle, D; Unde, W.-J., "Testing of Plastic Commodities. Migration of PVC Stabilizers into Edible 0i1", Nahrung, 13, 343-50, 1969. (German)

CA72-22347

27. Woggon, H.; Koehler, U.; Uhde, W.-J., "Testing of Plastic Commodities. Effect of Lubricants on the Migration Tendency of Organotin Compounds from Rigid PVC", Nahrung, 11, 809-17, 1967. (German) CA68-69831

28. Yen, C. H., "Quantitative and Qualitative Study of the Migration of Organotin Stabilizer from PVC to Liquid Foods", Rutgers State University, New Brunswick, N. J., Dissertation, 1970. CA75-128567 (Diss. Abstr. Int. B 1970, 31(3), 1343-4) 
NBS-114A (REV. 2-80)

U.S. OEPT. OF COMM.

BIBLIOGRAPHIC DATA

SHEET (See in structions)

1. PUBLICATION OR

REPORT NO.

NBSIR 81-2314

2. Performing Organ. Report Nof 3. Publication Dace

September 1981

4. TITLE AND SUBTITLE

"Migration of Low Molecular Weight Additives in Polymers"

5. AUTHOR(S)

L. E. Smith, S. S. Chang, and G. A. Senich

6. PERFORMING ORGANIZATION (If joint or other than NBS, see in structions)

NATIONAL BUREAU OF STANDARDS

DEPARTMENT OF COMMERCE

WASHINGTON, D.C. 20234

7. Contrace/Grant No.

FDA 224-77-2443

8. Type of Report \& Period Covered Seni-Annual

$10 / 1 / 80-3 / 31 / 81$

9. SPONSORING ORGANIZATION NAME ANQ COMPLETE ADDRESS (Street. City. State, ZIP)

Bureau of Foods

Food and Drug Administration

Washington, D.C. 20201

10. SUPPLEMENTARY NOTES

Related Documents: NBSIR 81-2264, NBSIR 80-1999

NBSIR 79-1779, 1598, 1499

Document describes a computer program; SF-185, FIPS Software Summary, is attached.

11. ABSTRACT (A 200-word or less factual summary of most significant information. If document includes a significant bibliogrophy or llteroture survey. mention it here)

Migration of three additives, n-octadecane, n-dotriacontane, and butylated hydroxytoluene (BHT), from linear (LPE) and branched polyethylene (BPE) into several $0 i 1$ simulating solvents is studied at 30 to $60^{\circ} \mathrm{C}$. Diffusion coefficients of the three migrants from BPE into n-octanol are about the same as those into ethanol. The diffusivity of BHT migrating from LPE into $n$-octanol is two to four times greater than that for ethanol extraction. Diffusion coefficients of the migrants from BPE into the synthetic triglyceride HB307 are about equal to those in ethanol and other triglycerides. Diffusivities for $95 \%$ ethanol extractions of BPE are reduced by a factor of two thirds to one half from the corresponding anhydrous ethanol values. The quantity of migrant extractable by $95 \%$ ethanol is more strongly governed by the change in partition coefficient, however. For BHT migrating from an (ethylene-5\% vinyl acetate) copolymer, diffusivities are only slightly higher for $n$-heptane but about three times greater in ethanol and corn oil extractions compared to those for BPE. A literature survey on the migration of organotin compounds, particularly di-n-octyltin stabilizers, from poly(vinyl chloride) into foods and food-simulants is also given.

12. KEY WORDS (Six to twelve entries: alphabetical order: capitalize only proper names; and separate key words by semicolons)

(Additives; diffusion; ethylene vinyl acetate copolymers; food additives; indirect

additives; migration; octyltins; organotins; polyethylene; polyolefins; poly(vinylchloride); PVC

13. AVAILABILITY

Q Unlimited

For Official Distribution. Do Not Release to NTIS

Order From Superintendent of Documents, U.S. Government Printing Office, Washington, D.C. 20402.

14. NO. OF PRINTED PAGES

41

X. Order From National Technical Information Service (NTIS), Springfield; VA. 22161

15. Price 
.

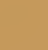


